\title{
Multiple Sports Sponsorships: Is More Always Better? An Abstract
}

\author{
Brett A. Boyle
}

\begin{abstract}
Brands which invest in sports sponsorships often sponsor a number of sports properties, many of which have fan bases with significant overlap. On the one hand, such investments in multiple properties may be done in hopes of achieving synergistic, positive effects for the brand. On the other hand, it could be argued that given high fan-base overlap, sponsorship investment in multiple sports properties is redundant and therefore an inefficient investment. A survey of 1,000 Americans focused on the effects of multiple sponsorships of a major US brand of antifreeze across three sports properties: NASCAR, NHRA, and the Professional Bull Riders (PBR) Tour. Awareness of one, two, or all three sponsorships was considered as a predictive variable with regard to outcomes of influence of the sponsorship toward brand preference and purchase intention. A MANOVA model revealed that sponsorship awareness had positive effects on purchase intention and that interactive effects were found in those cases an individual was aware of two sponsorships. Subsequent analysis was conducted to uncover how fan overlap across sports properties helps explain these synergistic effects.
\end{abstract}

B.A. Boyle $(\bowtie)$

Saint Louis University, St. Louis, MO, USA

e-mail: boyleba@slu.edu 